http://dx.doi.org/10.18232/alhe.alhe.1223

Artículos

\title{
El donativo de los hacendados de Nueva España para financiar la guerra de Sucesión española, 1709-1716
}

\section{The Donation of New Spain Landowners for Financing the Spanish Succession War, 1709-1716}

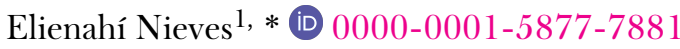 \\ ${ }^{1}$ Instituto de Investigaciones Dr. José María Luis Mora, Ciudad de México, México. \\ *Correspondencia: enieves@mora.edu.mx
}

Resumen. El presente trabajo estudia el donativo que se solicitó en 1709 exclusivamente a los dueños de propiedades productivas de Nueva España, con la finalidad de ayudar a los gastos de la guerra de Sucesión española. Se analiza la estrategia utilizada para solicitar recursos a ese grupo específico, así como los resultados obtenidos. Asimismo, se describen las tareas que las autoridades locales pusieron en práctica para recolectar las contribuciones. La negociación atravesó cada etapa de esta recolección y permitió a los implicados obtener o evitar lo que convenía a sus intereses, según fuera el caso.

Palabras clave: donativos; guerra de Sucesión; hacendados; fiscalidad extraordinaria.

Abstract. This work studies the donation that was requested in 1709 exclusively to the owners of productive properties in New Spain, in order to help with the expenses of the Spanish Succession war. The strategy used to request resources from that specific group is analyzed, as well as the results obtained. Likewise, it describes the tasks that the local authorities carried out to collect the contributions. The negotiation went through each stage of this collection and allowed those involved to obtain or avoid what was in their interests, as the case may be.

CÓMO CITAR: Nieves, E. (2021). El donativo de los hacendados de Nueva España para financiar la guerra de Sucesión española, 1709-1716. América Latina en la Historia Económica, 28(3), pp. 1-19. DOI: 10.18232/alhe.1223 
Key words: donations; Spanish Succession war; landowners; extraordinary taxation.

JEL: N36; N46; N86; N96.

Recibido: 07 de julio de 2020

Aceptado: 25 de enero de 2021

Publicado: 25 de junio de 2021

\section{INTRODUCCIÓN}

El objetivo de este artículo es contribuir al análisis de la política fiscal aplicada por Felipe V para financiar la guerra de Sucesión. En primer lugar, se expone el discurso mediante el cual se solicitaron contribuciones a un grupo en particular y se advierten las diferencias con los argumentos presentados en otras recolecciones de donativos. Asimismo, se presentan las diligencias particulares implementadas para esta recolección, así como la actuación de las autoridades involucradas en ella. En este estudio se evidencian las continuidades con los métodos aplicados por los Habsburgo. Por un lado, el recurso de solicitar donativos de los súbditos de Indias en caso de urgencia económica. Por otro, la política de la corona para obtener ingresos de emergencia a cambio de mantener los privilegios de los propietarios particulares.

Tras la muerte sin descendencia de Carlos II -el 1 de noviembre de 1700- la casa de Habsburgo de España se extinguió. El trono de la monarquía hispánica pasó a Felipe de Anjou, sobrino de Carlos II y nieto del rey francés Luis XIV. Se inauguró así el gobierno de la casa de Borbón sobre todos los territorios de la monarquía católica. Lo anterior no agradó al emperador Leopoldo I del Sacro Imperio Romano Germánico (nieto de Felipe III de España), quien alegaba el derecho de su hijo, el archiduque Carlos de Austria, a pesar de que su parentesco con la casa real hispánica era lejano. Tampoco les parecía bien a Gran Bretaña, Portugal ni a las Provincias Unidas, las cuales temían la unión de las coronas francesa y española, pues esto perjudicaría sus intereses. En 1701 se declaró la guerra de Sucesión por la corona hispánica, conflicto que perduró hasta que se firmaron los Tratados de Utrecht, en 1713.

Para financiar el conflicto bélico, el gobierno de Felipe $\mathrm{V}$ recurrió a distintos métodos, entre ellos a la bien establecida tradición de la dinastía Habsburgo de solicitar donativos a sus súbditos (Nardi, 2018a). El 25 de julio de 1701 se emitió una real cédula en la que se ordenaba reunir un donativo entre los vecinos de Nueva España para financiar la defensa de la plaza de Ceuta. ${ }^{1}$ Posteriormente, el 13 de marzo de 1705 se solicitó un donativo universal o general en España e Indias para sostener las operaciones de la guerra de Sucesión. ${ }^{2}$ Pero la solicitud que nos ocupa en este texto es la que se emitió el 10 de diciembre de 1709: el rey solicitó un donativo dirigido sólo a los dueños de haciendas, obrajes, trapiches, ranchos, estancias de ganado mayor y menor, ingenios y trapiches de azúcar, haciendas de labor y ejidos de molinos. ${ }^{3}$

La historiografía ha concentrado la atención en los caudales extraordinarios extraídos de las posesiones americanas con motivo del ciclo bélico del periodo finisecular del siglo XviII (Marichal, 1999; Nieves, 2018, 2020b; Torres, 2013; Valle, 1998, 2009, 2016a). Lo que ha llevado a

${ }^{1}$ AGN, Reales Cédulas Originales, vol. 30, exp. 50, fs. 149-149v.

${ }^{2}$ AGN, Reales Cédulas, vol. 32, fs. 232-233v.

${ }^{3}$ AGN, Reales cédulas, vol. 34, fs. 210-212. 
concluir, erróneamente, que fue un medio de exacción utilizado predominantemente por los últimos gobernantes de la casa Borbón al frente de la monarquía católica. No obstante, para financiar la guerra de Sucesión dinástica, Felipe V solicitó al menos cuatro donativos en los territorios de la monarquía.

Los donativos solicitados por los Habsburgo han sido estudiados sobre todo en su aplicación en España. ${ }^{4}$ Antonio Domínguez Ortiz presentó un recuento de los donativos solicitados durante el siglo XVII y sus modalidades de recolección, particularmente en el reinado de Felipe IV, algunos de los cuales fueron aplicados también en Indias (Domínguez, 1960). Además, se ha demostrado que este tipo de figuras fiscales también fueron usadas en Indias desde épocas muy tempranas (Bautista, 2020; Nardi, 2018a, 2018b).

Por otro lado, los donativos del consulado de mercaderes de México en las primeras décadas del siglo XviI han sido estudiados por Guillermina del Valle Pavón (Valle, 1997, 2016b, 2020); así como por Iván Escamilla (Escamilla, 2003, 2011). Así, el periodo que se estudia en este texto no ha recibido mucha atención en la historiografía, a pesar de su importancia para comprender la política fiscal de los primeros borbones y el acumulamiento de deuda que contraería Nueva España a finales de siglo.

\section{SOLICITUD DE RECURSOS A LOS PROPIETARIOS}

El 10 de diciembre de 1709, Felipe V solicitó un donativo dirigido sólo a los dueños de haciendas, obrajes, trapiches, ranchos, estancias de ganado mayor y menor, ingenios y trapiches de azúcar, haciendas de labor y ejidos de molinos. Las cantidades entregadas se destinarían a la financiación de la guerra de Sucesión. Se trataba de una solicitud diferente a las que el rey había hecho llegar a sus súbditos hasta entonces, por diversos aspectos. ${ }^{5}$ En primer lugar, no era un donativo general, más bien estaba dirigido a unos cuantos vecinos con características específicas. En este caso, que fueran dueños de propiedades productivas, con excepción de los eclesiásticos e indios. Es decir, sólo hacendados españoles o miembros de las castas y laicos debían entregar la contribución. Por otro lado, el donativo era por una cantidad específica, 50 o 100 pesos, tasada por el valor y dimensiones de la propiedad en cuestión. ${ }^{6}$

Cabe aclarar que esta no fue la primera ocasión en la que se solicitó un donativo en Nueva España a corporaciones o individuos específicos. Por ejemplo, en 1688 se pidió a los obispos y arzobispos un donativo para desalojar a los piratas del Mar del Sur. ${ }^{7}$ Tampoco se trató de la única vez en la que la corona planteó la contribución de donativos como alternativa a medidas más complicadas políticamente o gravosas económicamente. En 1608, los comerciantes hallados culpables de enviar a Nueva España mercancías sin registro tuvieron la oportunidad de evitar el secuestro de los bienes a cambio de un donativo voluntario (Nardi, 2018a, p. 22).

\footnotetext{
${ }^{4}$ Principalmente, se han estudiado sus características generales y algunos aspectos de negociación de donativos (Domínguez, 1960; Gelabert, 1997); así como su aplicación en territorios con fuero (Truchuelo, 2008, pp. 283-300). Sin dejar fuera estudios de casos concretos de recolecciones y sus mecanismos (Gil, 2015; Lanza, 2010). En la península, la negociación que podía implicar la recolección de donativos se veía influenciada por otros medios de exacción, como el secuestro de la plata que habían traído los galeones o la retención de los intereses de los juros. En América, las recolecciones de donativos solían relacionarse con otros recursos extraordinarios, como los préstamos, suplementos y subsidios.

${ }^{5}$ Para un estudio de las solicitudes de donativos enviadas a Nueva España en 1701, 1705 y 1710, véase Nieves, 2020a.

${ }^{6}$ AGN, Reales cédulas, vol. 34, fs. 210-212.

${ }^{7}$ AGN, Reales cédulas originales, vol. 22, exp. 60.
} 
La corona también había recurrido con anterioridad a los propietarios de tierras para obtener recursos en tiempos de urgencias. El 17 de mayo de 1631, con la presión económica que significaba la guerra de los Treinta Años, Felipe IV expidió una cédula de composición de tierras aplicable en Indias. La instrucción era que se regularizaran las tierras en las que se hubiera introducido y usurpado más de lo que les pertenecía, a cambio de una "moderada composición" o que se vendiera y rematara al mejor postor. Pero el proceso no fue exitoso, ya que fueron más los costos que lo que se logró recabar (Goyas, 2015, pp. 60-61; Torales, 2005, pp. 54-55).

Para cumplir la orden del rey, en 1643 el virrey de Nueva España, conde de Salvatierra, promovió las llamadas composiciones colectivas, las cuales consistían en que una sola composición grupal era suficiente para los vecinos de toda un área administrativa. Posteriormente, los labradores prorrateaban las contribuciones entre ellos. Por ejemplo, los labradores de Cholula ofrecieron 14000 pesos para que se confirmaran y compusieran sus tierras, pero prorratearon 16206 pesos en total, para cubrir los gastos administrativos. En este proceso de consolidación, que concluyó hasta 1645, la corona aseguró 509103 pesos para la construcción de la Armada de Barlovento (Goyas, 2015, pp. 62-64; Torales, 2005, pp. 58-60).

El 27 de junio de 1692 se emitió otra cédula para que los virreyes de Nueva España y Perú organizaran una nueva composición de tierras. Los representantes de los labradores aludieron al pacto que habían hecho con el rey en 1643 pero se argumentó que desde entonces habían surgido nuevas propiedades o crecido las existentes. Los propietarios tuvieron que llegar a acuerdos con las autoridades. Por ejemplo, los vecinos de Cholula ofrecieron 500 pesos, por vía de donativo, para la asistencia de los ejércitos reales. Desembolsaron 1455 pesos: el donativo más los gastos de las diligencias del subdelegado y quienes le asistieron, los cuales resultaron más costosos que la donación al real erario (Torales, 2005, pp. 63-66).

El 15 de agosto de 1707, Felipe V expidió una cédula en la que comisionó a Francisco Ramírez de Arellano, del Consejo de Indias y Junta de Guerra para "recaudar [...] lo más que pertenezca en estas Indias al Real Patrimonio y se posea sin título ni justa causa, con exceso y demasía, con vicio, defecto..." El dinero obtenido se aplicaría para la defensa de la monarquía en el escenario de la guerra de Sucesión, y aquello que no se legalizara, se ofrecería en remate al mejor postor (Torales, 2005, pp. 69-70). Cabe mencionar que Francisco Ramírez conocía bien los mecanismos de negociación mediante de donativos. Así lo confirma el indulto que obtuvo en 1715 por el asesinato de Diego Vela, a cambio de un "servicio" de 7000 pesos. ${ }^{8}$

En cualquier caso, la composición de 1707 revela aspectos interesantes de las negociaciones que se presentaban entre los propietarios y las autoridades. Para empezar, confirma la constante referencia de los propietarios a la composición de 1643, a lo cual el fiscal de la Audiencia argumentaba que este arreglo había sido una generalidad y no expresaba el número de vecinos ni se habían exhibido los títulos. Por otro lado, aunque los vecinos aludieran a servicios anteriores, si estos se habían entregado en calidad de "donativo gracioso", se diferenciaban de la composición de la tierra (Torales, 2005, pp. 78-79).

Contrario a lo que había ocurrido en las composiciones anteriores, en 1707 se solicitó que también los pueblos de indios presentaran sus títulos de propiedad. Pero aun los propietarios de haciendas, ranchos, molinos, etc. tuvieron que obedecer la real cédula. Ejemplificamos con el caso de Cholula, ya que este ha sido mejor estudiado. El 26 de marzo de 1710 los propietarios de Cholula entregaron poder a Antonio Pavón para gestionar ante Francisco de Valenzuela Venegas,

${ }^{8}$ AGI, México, 486B, f. 254. 
oidor más antiguo de la Audiencia de México y juez privativo de composiciones, que suspendiera las diligencias para la composición de tierras. Los pueblos de indios también enviaron representantes con el mismo propósito. La razón de esta solicitud era que en todas las jurisdicciones de Nueva España estos trámites resultaban muy costosos y eran los propietarios quienes debían cubrir aquellos gastos. Los vecinos tenían que pagar los salarios de todos los ministros que se enviaran para comprobar las irregularidades: juez, escribano, agrimensor. Por ello, parece que resultaba más sencillo y menos oneroso para los vecinos negociar una contribución que les evitara el papeleo. Esta parece ser también la razón por la cual los propietarios cooperaron con los donativos que les solicitaron en 1709, a pesar de que esta recolección resultó simultánea a la orden de composición de 1707. Entre 1711 y 1717, los particulares mostraron sus títulos de propiedad para obtener decretos de confirmación y composición. La entrega de donativos pudo facilitar la resolución de los expedientes de composición.

Pero enfoquémonos ahora en el donativo de los propietarios de Nueva España. Como es bien sabido, las haciendas formaban parte trascendental de los sistemas comerciales y financieros de Nueva España. La economía, conectada globalmente a través del comercio pacífico y atlántico, dependía en gran medida de la producción agropecuaria de estas unidades productivas que también abastecían los reales mineros. La hacienda es definida como una propiedad rural explotada mediante trabajo subordinado, con la ayuda de un capital que podía no ser tan grande. Las ambiciones del hacendado respecto a su propiedad eran la acumulación de capital, pero también el adelantamiento social, lo que redundaba en poder político. Un factor importante para la influencia de estos propietarios era que, normalmente, ocupaban los puestos de autoridad locales. Es decir que los hacendados aspiraban -y en muchas ocasiones lograron- el dominio de una región (Mörner, 1975, pp. 17-26; Wobeser, 1989, pp. 50-52, 63-64). ¿Cómo lograr la cooperación de estos poderosos propietarios?

El discurso que se utilizó es digno de análisis. Esta vez el rey no comenzó como en las cédulas que había expedido anteriormente para solicitar donativos: con la bien conocida explicación de la urgencia de las necesidades financieras y la justicia de la guerra que se libraba. Ahora el argumento principal involucraba el servicio de 3000 pesos que un tal Juan de Barreneche entregó de contado. En atención al desembolso, en decreto de 31 de agosto de 1709, se le concedió la visita de las jurisdicciones de las Audiencias de México y Guadalajara. El Consejo de Indias recalcó los perjuicios que, de enviar a Barreneche, podrían resultar a los vasallos de esos dominios, "por las violencias, tiranias, injusticias y extorsiones que experimentarian de quien no podria llevar ôtro que el de utilizarse a costa de ellos". ${ }^{9}$

En consideración a sus súbditos, el rey resolvió anular la comisión. Por tanto, ordenaba al virrey, duque de Alburquerque, que informara a todos los hacendados de Nueva España -“a quienes comprendia la vicita que habia concedido"- para que en vez de recibir un visitador que podía resultar tan perjudicial, entregaran un donativo gracioso para las urgencias de la guerra. Se trataba de una contribución por una vez y de una cantidad determinada: 50 pesos las haciendas menores y 100 las mayores. ${ }^{10}$ Probablemente la aportación se restringió a estas cantidades en un intento por recaudar la mayor cantidad posible. Aunque los grandes hacendados pudieron haber donado más de 100 pesos si el donativo se dejaba a su arbitrio, eran más abundantes las propiedades pequeñas, por lo que la suma de sus donativos por 50 pesos eran un ingreso considerable.

${ }^{9}$ AGN, Reales cédulas, vol. 34, fs. 210-212.

10 AGN, Reales cédulas, vol. 34, fs. 210-212. 
Claramente, esta es otra diferencia importante que distingue esta solicitud. El resto de los donativos solicitados por Felipe $\mathrm{V}$ habían sido por una cantidad voluntaria, pero esta ocasión se estipularon dos cuotas fijas, de acuerdo con el valor de las propiedades. También es claro que, aunque se le atribuyera el calificativo de "voluntario", esta ocasión en particular difícilmente se le puede aplicar apropiadamente. Otra encomienda para el virrey fue que se asegurara que los alcaldes mayores realizaran un censo de las haciendas de sus jurisdicciones para tasar la contribución, así como para "proceder contra los dueños que voluntariamente no dieren la contribución". ${ }^{11}$

Los visitadores eran enviados a la búsqueda de malas prácticas administrativas, a verificar las condiciones de la localidad y a aplicar justicia, de considerarlo necesario, y de todo ello tenían que enviar una relación al Consejo de Indias. Parece seguro que los hacendados estaban interesados en librarse de problemas legales debido a sus prácticas; como apropiaciones de tierras de pueblos de indios, uso indebido de aguas o pastizales que no les pertenecían, tierras fuera de composición, abusos a sus trabajadores... Las dificultades que podían evitar con un donativo que mantuviera alejado a Juan de Barreneche pudieron ser muchas. Resultaba más sencillo entregar 50 o 100 pesos, según el valor de la propiedad, y eludir así cualquier inconveniente. Incluso, en la cédula especifica que estas "cantidades son sumamente moderadas a vista de que con muchos mayores contribuyrian al Juez visitador, por escusar las molestias”. ${ }^{12}$ Más aún cuando tenemos noticia de que en 1702 se había nombrado otro visitador para todos los obrajes, ingenios y trapiches del obispado de Puebla de los Ángeles, donde se encontraba la mayor concentración de haciendas cerealeras (Wobeser, 1989). ${ }^{13}$

Tratemos de entender un poco mejor quién era Juan de Barreneche y por qué el rey le usó (al menos en la retórica) para extraer caudales de los hacendados de sus dominios de ultramar, incluidas las islas Filipinas. ${ }^{14}$ La primera noticia de Barreneche se encuentra en una certificación de la Casa de Contratación, del año 1699, en la que se le autorizaba embarcar en cualquier navío de la flota próxima a partir hacia Nueva España mercaderías por valor de más de 200000 maravedíes. $^{15}$ A fin de obtener permiso para pasar al reino de Nueva España, Juan ofreció su información y testigos. Tenía 25 años y era originario de la villa de Lesaca, una de las cinco montañas de Navarra, hijo legítimo de Miguel de Barreneche y Catalina de Oreindan. ${ }^{16}$

Barreneche aparece nuevamente en 1706 en los registros de la Casa de Contratación, esta vez para pasar a Nueva España en la flota de Diego Fernández de Santillán. ${ }^{17}$ En aquella ocasión llevaba mercancías cuyo valor principal había importado 24709 pesos, pertenecientes a Fernando Morillo Valdivia, vecino de Cádiz. Por aquel documento sabemos que Barreneche también tenía negocios en Tierra firme. Con su participación en el comercio atlántico, Barreneche logró hacerse de algún capital, pues lo siguiente que se sabe de él es que otorgó 3000 pesos de contado como

11 AGN, Reales cédulas, vol. 34, fs. 210-212.

12 AGN, Reales cédulas, vol. 34, fs. 210-212.

13 AGI, Escribanía, 233A.

${ }^{14}$ A pesar de que Juan de Barreneche había sido nombrado visitador de las Audiencias de México y Guadalajara, también en las islas Filipinas se recolectó un donativo entre los hacendados. Se tiene noticia de al menos 2085 pesos entregados por los propietarios del archipiélago. Para un análisis de esta recolección, véase Nieves (2020a).

15200000 maravedíes equivalían a unos 666 pesos de a ocho, pero en la fuente no se especifica a cuánto "más" ascendía el valor de las mercancías.

16 AGI, Contratación, 5459, N. 158.

${ }^{17}$ La primera flota que surcó el Atlántico con dirección a Nueva España en el siglo XviII (Pérez-Mallaína, 1982, pp. 9-11). 
donativo por el puesto de visitador de las Audiencias de México y Guadalajara. Merced que no llegó a ejercer porque el rey consideró más fructífero pedir a los hacendados que entregaran donativos a cambio de librarlos de la visita. ${ }^{18}$

El servicio de Juan de Barreneche a la corona tampoco fue en vano. En 1711 recibió la merced de futura en la plaza de contador de Real Hacienda en la caja de Panamá. ${ }^{19}$ Así, queda claro que la entrega de donativos se insertaba en la economía de la gracia. La fiscalidad era una arena de negociación en la que los participantes procuraban obtener o evitarse algo, según la conveniencia.

Es importante señalar que, a pesar de la peculiaridad de esta solicitud, no se hallaron quejas al respecto. Aparentemente, la legitimidad de este donativo no fue puesta en duda. Más bien, como se verá en el siguiente apartado, gran cantidad de dueños de propiedades entregaron contribuciones.

\section{ResPuesta de los hacendados De Nueva EsPaña}

Para comenzar con la recolección, el virrey Alburquerque ordenó que se enviaran despachos a todas las jurisdicciones para que sus gobernadores, corregidores y alcaldes mayores formaran relaciones de todas las haciendas, con estimación de su valor, nombres de sus dueños, de los arrendatarios -en caso de haberlos- y de la cantidad que pagaban por ellas. Al mismo tiempo, el virrey contestó las dudas que le surgieron al presidente de la Real Audiencia de Guadalajara y por ello decretó que quedaban excluidas de este servicio las haciendas de minas y sus molinos; en virtud de que estas "continuamente están acudiendo a S. M. con los derechos de quintos y diezmos y por ser el principal nervio del reino”. Siempre y cuando sus dueños fueran efectivamente mineros. ${ }^{20}$

Las diligencias que comenzó a implementar Alburquerque tuvieron lugar en los primeros días de agosto de 1710. Para entonces, el virrey ya había solicitado permiso al rey para regresar a España a atender su quebrantada salud. El 10 de octubre de 1710, pisaba el puerto de Veracruz quien sería su relevo: el duque de Linares. Un mes después el nuevo virrey entró en la Ciudad de México y tomó posesión formalmente del cargo. ${ }^{21}$

El duque de Linares recibió una urbe herida por una epidemia reciente y un virreinato que había entregado repetidos donativos con motivo de la guerra y del nacimiento del príncipe. ${ }^{22}$ Aunque, cabe decir, que no por ello pareciera un territorio exhausto, más bien había logrado donar lo menos posible, sin dejar de cumplir con sus obligaciones ante el rey. ${ }^{23}$

Como sea, aún estaba pendiente la recolección del donativo que Felipe V solicitaba a los hacendados. El 18 de julio de 1711, el virrey repitió las órdenes a los alcaldes mayores para que enviaran las relaciones de haciendas existentes en sus respectivas jurisdicciones. Ya que había pasado demasiado tiempo sin que se cumpliera esta encomienda, impuso una multa de 500 pesos a

18 AGI, Contratación, 5463, N. 41. Fernando Valdivia participaba del comercio de la flota al menos desde finales del siglo anterior. En 1695 embarcó hacia Nueva España, mediante varios factores, mercancías por un valor de 500000 maravedíes. AGI, Contratación, 5456, N. 2, R. 24 y AGN, Reales cédulas, vol. 34, fs. 210-212.

19 AGI, Contratación, 5466, N. 1, R.7.

20 AGI, Contaduría, 784B, fs. 309-336.

21 AGI, México, 485, f. 433.

22 AGI, México, 484, N. 24.

${ }^{23}$ Sobre todo, resulta de interés la intensa negociación de los miembros del Consulado de México para contribuir en la recolección de donativos de 1701, véase Valle, $2016 \mathrm{~b}$. 
quienes continuaran en omisión de sus deberes. ${ }^{24}$ Aunque, a instancias del fiscal de la Real Audiencia, posteriormente esta multa fue establecida en 100 pesos, la cual se aplicarían a las obras de reconstrucción del Palacio de la corte de México. ${ }^{25}$

Asimismo, el virrey tuvo que establecer claramente los parámetros para tasar las contribuciones. Una hacienda "grande", que tenía que contribuir con 100 pesos, era la que tuviera un valor mínimo de 5000 pesos. Mientras que se considerarían como chicas aquellas cuyo valor fluctuara entre los 1000 y los 5000 pesos; estas tenían que entregar 50 pesos. $^{26}$

Entre diciembre de 1710 y julio de 1714 entraron en las cajas de Nueva España 62654 pesos como donativos de los dueños de haciendas. Este fue el primer envío a la metrópoli, pero la recolección continuó. Las instrucciones del virrey especificaban que las contribuciones debían registrarse con el nombre del donante; a fin de llevar un registro de quienes ya habían donado, quienes aún adeudaban e, incluso, para que aquellos que hubieren dado más de lo requerido pidieran una restitución. ${ }^{27}$

Si la información efectivamente se conformó de esa manera, los documentos resultantes no fueron hallados para esta investigación. La mayoría de los donativos se registró a nombre del alcalde mayor que llevó a cabo la recolección; así que en el cuadro 1 se presentan estas contribuciones por jurisdicción (véase cuadro 1, anexo). Sin embargo, en aquella relación de donativos también aparecían algunos entregados por vecinos particulares (véase cuadro 2 , anexo).

Por supuesto, las jurisdicciones con las tierras más fértiles o con mayor concentración de haciendas ganaderas, obrajes, molinos, etc., entregaron los donativos más cuantiosos, como las que se ubicaban en el Bajío y la meseta central. El mayor donativo provino de las jurisdicciones de Celaya y Salvatierra, las cuales se encontraban en una zona descrita como "muy fértil y pingue de frutos", con abundancia de haciendas agrícolas y ganaderas (Alcedo, 1789, p. 136).

Cholula, en las faldas del Iztaccíhuatl, era una zona mayormente agrícola. En la primera mitad del siglo XviII había 55 propiedades de particulares: 25 haciendas y 32 ranchos, de los cuales cinco estaban integrados a otra propiedad; dos como molinos y dos como batanes (Gerhard, 1986, pp. 117-118; Torales, 2005, p. 87). Por otro lado, en Tlaxcala abundaban las haciendas y labores de trigo, así como los obrajes. Debido a su suelo fértil, abundaban las frutas, hortalizas y era propicio para la cría de ganado. ${ }^{28}$ Atlixco, una amplia llanura irrigada por varias corrientes del río Atoyac, también albergaba muchas haciendas de españoles en las que se cultivaba, sobre todo, trigo (Gerhard, 1986, pp. 56-58). Todas las cabeceras antes mencionadas se encontraban en la Alcaldía Mayor de Tepeaca, donde a mediados del siglo XviI se contaban más de 300 haciendas; para 1791 habría 100 más. La mayoría de las propiedades eran cerealeras, fundamentalmente de maíz y trigo y, en segundo lugar, de cebada (Garavaglia y Grosso, 1994, pp. 147-150, 198).

24 AGI, Contaduría, 784B, fs. 309-336.

${ }^{25}$ En 1692 el Palacio se destruyó parcialmente debido a un incendio. Los tribunales permanecieron en la parte que no sufrió daños, pero los ministros solicitaron repetidas ocasiones que se reparara el edificio. En 1709 la Audiencia de México se trasladó al edificio de la Real Universidad y la reconstrucción comenzó. Véase AGI, México, 485, fs. 646-688.

${ }^{26}$ AGI, Contaduría, 784B, fs. 309-336.

27 AGI, Contaduría, 748B fs. 309-336.

${ }^{28}$ Gerhard apunta que en 1791 había 243 haciendas, pero no tenemos datos de la primera parte del xviII. Sin embargo, las cifras demográficas nos hablan de un constante crecimiento de la región a partir del siglo XVII (Alcedo, 1789, p. 154; Gerhard, 1986, pp. 333-335). 
Entre los donativos de particulares podemos mencionar el de Fernando Altamirano de Velasco, conde de Santiago, quien donó 350 pesos por sus haciendas. El conde tenía motivos para apresurarse a obedecer al rey. En 1698 protagonizó un escándalo que le valió un castigo ejemplar por parte del virrey José Sarmiento Valladares, conde consorte de Moctezuma. La esposa de un ministro real se escapó de su hogar para vivir con el conde de Santiago, lo que había sido tolerado por más de cinco años. Sin embargo, el virrey no pensaba pasar por alto semejante "gravissimo delito". Ordenó al conde que recluyera a la mujer en un convento, pero cuando esta se escapó (con ayuda del conde), Sarmiento tomó otras medidas. El conde de Santiago fue exiliado en el castillo de San Juan de Ulúa durante seis meses. Sólo salió de ahí cuando la mujer, embarazada, aseguró que se quedaría en el convento de Santa Clara. Con todo, el conde no podía salir de sus haciendas sin el consentimiento del virrey. El conde de Santiago había desafiado la autoridad del virrey, razón por la cual fue severamente reprendido. A fin de ganar nuevamente el favor real tenía que demostrar su fidelidad en todo asunto relacionado con el servicio a la corona. ${ }^{29}$

Cabe destacar también el donativo de Alonso Dávalos Bracamonte, conde de Miravalle y prior del Consulado entre 1704 y 1706, quien entregó 150 pesos por las haciendas Nuestra Señora de la Concepción y las de la Lagunilla. Los Dávalos Bracamonte habían aplicado una efectiva estrategia para consolidar su fortuna. Esta consistió en proteger sus negocios mediante la diversificación: como comerciantes, productores agropecuarios y mineros; esta última actividad poco usual entre los mercaderes del consulado. Por otro lado, los servicios pecuniarios entregados al rey ganaron su favor y le facilitaron formar un mayorazgo que preservó su patrimonio, así como un título nobiliario que les añadió prestigio social (Garritz, 1993, pp. 45, 55; Valle, 2020, pp. 138-145). ${ }^{30}$

Luis Luyando y Bermeo donó 100 pesos por su hacienda de ovejas en Tlazazalca. Este comerciante también había alcanzado gran renombre en la capital del virreinato: fue nombrado rector de la cofradía Nuestra Señora de los Remedios desde 1692 y regidor de la ciudad de México en 1726, cargo que ocupó hasta $1730 .{ }^{31}$ Sus servicios en el gobierno, así como la presteza a auxiliar para las necesidades económicas de la monarquía, sin duda le ayudaron para granjearse estos honores. Don Luis logró formar un mayorazgo que, años después fue motivo de litigio para sus herederos. $^{32}$

En 1707, el general Antonio Fernández del Rivero adquirió la hacienda conocida como San Cristóbal de Solano y Mojarrillas, compuesta por doce sitios de ganado mayor, en la frontera de Santa Catarina Mártir, San Luis Potosí. Dos años después, cooperó con 100 pesos para la financiación de la guerra, a cambio de evitar una visita a sus tierras. La propiedad fue rematada por el capitán Bartolomé Pérez de la Cruz. ${ }^{33}$

${ }^{29}$ El conde de Santiago de Calimaya sirvió como corregidor en ínterin de la ciudad de México a partir del 27 de diciembre de 1680; fue nombrado propietario en el cargo el año siguiente, con grandes elogios a su labor. Véase AGI, México, 52, N.18. AGi, México, 66, R. 3, N. 67. En 1701, para el donativo destinado a la defensa de Ceuta, el conde de Santiago donó 500 pesos (Escamilla, 2003, p. 51).

${ }^{30} \mathrm{El}$ conde de Miravalle tenía toda intención de convertirse en un importante terrateniente, pues en 1715 ya poseía otras dos haciendas, en la misma jurisdicción de Querétaro: Zamorano y Atongo. AGN, Tierras, vol. 2765 , exp. 4.

${ }^{31}$ Actas de Cabildo de la Ciudad de México. Recuperadas de https://www.bib.ibero.mx/actasc/collections/show/1

32 AGN, Tierras, vol. 2965, exp. 22.

33 AGN, Tierras, vol. 2707, exp. 4. 
Finalmente, llama la atención que, a pesar de que las órdenes especificaban entregar 50 o 100 pesos, Francisco Gorráez Beamont y Navarra sólo entregó 32 pesos. ${ }^{34}$ No se hallaron fuentes que comprueben que se hizo acreedor a algún tipo de sanción. Muy probablemente, como en otras recolecciones de donativos, los vecinos podían negociar o excusarse mediante la acreditación de su imposibilidad para donar más (Nieves, 2018, 2020a, 2020b).

Como ya se mencionó, la recolección continuó en el gobierno del duque de Linares, aportaciones que se enviaron a España hasta 1716. En total, los propietarios de Nueva España contribuyeron con 131515 pesos para la financiación de la guerra de Sucesión. ${ }^{35}$ Una contribución bastante considerable si se le compara con los otros donativos solicitados por Felipe $\mathrm{V}$ para la financiación de la misma guerra. En obediencia a la real cédula de 1701, los vecinos de Nueva España entregaron 375631 pesos. En 1705 donaron 95194 pesos. Mientras que en 1710 se enviaron 75944 pesos como donativo para la construcción de navíos. Todos estos otros donativos fueron universales. Es decir, todo súbdito del rey debía contribuir; españoles indios y castas (Nieves, 2020a).

\section{DiligenCIAS PARA RECOLECTAR LOS DONATIVOS DE LOS HACENDADOS}

En la propia cédula en la que se solicitaron los donativos de los dueños de propiedades productivas de Nueva España se especificó que los gobernadores, corregidores y alcaldes mayores tenían varias tareas que cumplir como mediadores para recolectar y hacer llegar las contribuciones. En primer lugar, como recaudadores de datos poblacionales. Estas autoridades locales debían formar listas de las haciendas que se encontraban en sus jurisdicciones, con distinción del tipo de hacienda de que se trataba, extensión y valor aproximados, así como el nombre de su dueño, mayordomo o administrador. En caso de que en la jurisdicción no hubiera haciendas, los justicias locales debían informar al gobierno virreinal. Como lo hizo el alcalde de Tlaxcala, quien detalló que los únicos trapiches en su provincia pertenecían al presbítero Andrés de las Horas, pero por su calidad de eclesiástico quedaba exceptuado del donativo. ${ }^{36}$

La utilidad de estas relaciones era múltiple: primero para solicitar las contribuciones, y después para cotejar estos listados, los cuales se formaban con los donantes y las cantidades que habían entregado. Una vez que se recopilaban los datos de las haciendas en cada jurisdicción, eran las mismas autoridades locales quienes se encargaban de informarles la solicitud del rey y -en calidad de agentes fiscales- de recolectar los donativos. Al recaudar las contribuciones formaban la lista de donantes y contribuciones. Todas estas diligencias debían llevarlas a cabo como parte de sus obligaciones y no cobrar ningún derecho ni costas, práctica que sin embargo era común entre los alcaldes y corregidores para aumentar sus ganancias. Con todo, los casos de composiciones de tierras expuestos en el primer apartado de este texto nos muestran que los vecinos preferían entregar donativos, muy probablemente porque los costos administrativos eran menores. ${ }^{37}$

34 AGI, Contaduría, 748B fs.327-336.

35 AGI, Contaduría, 748B fs. 309-336.

${ }^{36}$ AGN, Indiferente Virreinal (Reales Cédulas), caja 4118, exp. 013.

${ }^{37}$ AGI, Contaduría, 784B, fs. 309-336. Acerca de los sueldos y prácticas de las autoridades locales para incrementar sus ingresos, véase Borah (2002, pp. 50-64). AGN, Reales cédulas, vol. 34, fs. 210-212. 
Finalmente, gracias a los informes que prepararon, podían "proceder contra los dueños que voluntariamente no dieren la contribución”. Así, también aplicaban su facultad judicial. Aunque el decreto que Alburquerque envió a los alcaldes mayores no detalla cómo se procedería contra los hacendados, más bien dice que los donativos debían reunirse "sin apremio ni violencia" ${ }^{38}$

Como se mencionó brevemente en el apartado anterior, en el transcurso de la recolección, las autoridades locales de Nueva España expresaron al virrey las dudas que les habían surgido. Uno de los asuntos que no quedaba claro era qué criterios usar para calificar a una hacienda como chica o grande y así determinar la contribución que debía entregar. En real acuerdo se decidió que, si se atendían los casos particulares, la exacción sufriría retrasos inadmisibles. Por lo tanto, tenían que establecerse parámetros "de todos generos de haciendas", para lo cual se instruyó a los alcaldes mayores y corregidores que formaran mapas con la ubicación de cada propiedad, así como bosques, ganados, aperos y esclavos que influyeran en su valor. Pero la "ausencia o negligencia" de los alcaldes había provocado que muchos no cumplieran con su encomienda o que sus informes estuvieran hechos con "tal desorden y confusión que casi parece necesario repetirlos". Con los pocos mapas que llegaron al gobierno virreinal se resolvió que cada una de las haciendas de ganado mayor, agostaderos, trasquila, matanzas, obrajes de pinos y palmeras, de granos, ingenios de azúcar y molinos de pan, cuyo valor llegara a 5000 pesos o más contribuyeran con 100 pesos de donativo y las de entre 1000 y 5000 pesos de valor se consideraran haciendas de menor terreno y, por lo tanto, donaran 50 pesos. ${ }^{39}$

Queda claro que la exacción de recursos adicionales a las rentas reales también era obligación de los gobernadores provinciales, además de un asunto apremiante. Si las autoridades locales se demoraban en la recolección de los donativos, a pesar de haber recibido ya dos decretos, de dos virreyes diferentes, se les haría "el cargo correspondiente a su omision y poca inteligencia". Se les advirtió también que si rebajaban la tasación de las haciendas se les multaría con 500 pesos. Para ello, Francisco de Valenzuela Venegas, oidor más antiguo de la Real Audiencia y juez privativo de composiciones de tierras y aguas, fue instruido para dar certificación de todas las haciendas que constare haber en cada jurisdicción, sus especies y calidad. ${ }^{40}$

Una prueba adicional de la importancia del papel de estos mediadores locales es el hecho de que los donativos entregados en las cajas reales también registraban el nombre de quien los había recolectado o transportado. Esto era un registro valioso para probar sus servicios al rey y solicitar algún tipo de merced o contraprestación.

Una vez recolectados los donativos en las distintas jurisdicciones, las autoridades locales debían encargarse de remitirlos a las cajas reales. Para cumplir este fin, se esperaba la ocasión en la que se enviaban las rentas reales, lo cual se realizaba cada cuatro meses. Sin embargo, era común retrasar los depósitos en el tesoro real para poder invertir los fondos en negocios particulares. Después, los alcaldes mayores presentaban las cuentas bajo el concepto de "rezago". El método de envío podía variar. Ya que en la mayoría de los casos las contribuciones se entregaban en metálico, podía recurrirse a contratar a los conductores de platas reales, mediante libranzas o con un depósito en cajas reales ejecutado por un comerciante con quien el alcalde o corregidor tenía tratos (Yuste, 2002, pp. 133-134).

38 AGN, Reales cédulas, vol. 34, fs. 210-212; AGI, Contaduría, 784B, fs. 309-336.

39 AGI, Contaduría, 784B, fs. 309-336.

40 AGI, Contaduría, 784B, fs. 309-336. 
Uno de los principales obstáculos para estos envíos eran las grandes distancias. En Nueva España los caudales debían concentrarse en la caja de México, para formar la relación que se enviaría a Madrid; pero en 1710 el alcalde mayor de Tlaxcala consideró que era mejor enviarlos directamente a las cajas de Veracruz, que estaba mucho más cerca de su jurisdicción. Además, argumentó que no había "ningun comercio" del cual valerse para el transporte a la capital. ${ }^{41}$ Habría que poner en duda esta afirmación, pero nos confirma que, entre las provincias, el dinero del rey seguía la misma ruta de las mercancías, como circuito articulador de los espacios económicos.

Sin embargo, el transporte no era ni mucho menos infalible en su misión de hacer llegar los donativos al rey. En enero de 1718, el Consejo de Indias emitió una consulta sobre el paradero de 26543 pesos que se cobraron del donativo de la Audiencia de Guadalajara. En una carta fechada el 3 de diciembre de 1712, el presidente de la mencionada Audiencia, Toribio Rodríguez de Solís, remitió dos partidas de donativos: 19522 pesos donados por los hacendados de las jurisdicciones bajo su mando, y los 7022 restantes para el donativo que se solicitó en 1710 para la fábrica de bajeles (Nieves, 2020a). La certificación de los oficiales de la caja de México avala que el dinero se entregó en la capital, pero en la carta cuenta de los oficiales de Veracruz sólo se incluían 4279 pesos remitidos desde Guadalajara “y otras diferentes alajas sin declarar del motivo de su entero". No se volvió a tener noticia de los caudales. El documento no menciona quién fue el encargado de transportarlos desde la capital al puerto, pero en el camino se "perdieron". ${ }^{42}$

\section{Conclusiones}

Envuelta en un conflicto bélico de proporciones globales, como lo fue la guerra de Sucesión dinástica, la monarquía católica requería de caudales urgentes para el fortalecimiento del aparato militar. Los medios escogidos para este fin debían permitir la pronta recaudación de los fondos necesarios. Los donativos fueron elegidos entre ellos porque cumplían con este requisito y, además, tenían la ventaja de no exigir retribución monetaria.

En este texto se estudió una solicitud que apelaba a argumentos diferentes de los habituales, pero la lógica de su recolección se sustentó en los mismos preceptos en que descansaban los donativos universales o generales. Eran una ayuda al rey necesitado de caudales para defender la monarquía y la religión católica. Sin embargo, aunque los donativos se solicitaban con un sustento discursivo de gran tradición, al final eran una relación económica. Por una parte, los súbditos que contribuían a la conservación de la monarquía; por otra, el rey, quien agradecía con privilegios y exenciones que eran posibles gracias al orden que sustentaban los caudales entregados.

Juan Barreneche, verbigracia, donó 3000 pesos de contado a la Real Hacienda. Él entregó metálico, pero no recibió lo mismo a cambio. En lugar de moneda, consiguió la promesa de generarla, con un empleo en la administración real. Por otro lado, los hacendados que cedieron caudales obtuvieron la exención de procesos que pudieran ocasionarles penas pecuniarias. El rey también se benefició de este trato: no sólo obtuvo los 3000 pesos pagados por el puesto de visitador en las Audiencias de México y Guadalajara -aunque ulteriormente se convirtió en uno de contador de Real Hacienda en la caja de Panamá-, sino que negoció un donativo de parte de los hacendados

41 AGN, Indiferente Virreinal (Reales Cédulas), caja 4118, exp. 013.

42 AGN, Reales Cédulas Originales, vol. 39, exp. 50, fs. 114-116v. 
por el que retribuyó con la cancelación de una visita a sus propiedades. El precio, entonces, no necesariamente era idéntico, pero en aquel sistema económico era equitativo, ya que se encontraba atravesado por relaciones políticas.

El total recolectado por la cédula de 1709 -131 515 pesos- resultó bastante considerable, sobre todo porque que no se trató de un donativo universal, como el resto de las recolecciones organizadas por orden de Felipe V. El primer donativo que solicitó en Nueva España el nuevo rey borbón de la monarquía hispánica, en 1701, recaudó 375631 pesos. Cuatro años después, los vecinos de Nueva España entregaron 95194 para los gastos de guerra. Finalmente, en 1710 el monarca solicitó la ayuda de sus súbditos para construir navíos que escoltaran a la flota de Indias. Nueva España envió 75944 pesos como contribución a esta causa.

En las recolecciones en las que se dejaba al libre arbitrio de los súbditos la cantidad con la que contribuyeran, la amplitud social de la respuesta era la clave para recolectar grandes caudales. En 1709, Felipe V apostó por una cantidad determinada como donativo de los propietarios de los medios de producción. Los hacendados cooperaron a cambio de que aquel desembolso les preservara sus privilegios y les evitara mayores gastos y problemas administrativos.

Así, la política aplicada por Felipe $\mathrm{V}$ pareció eficaz en tanto tuvo acceso a plata americana que desahogaba al real erario en sus muchos gastos bélicos. Además, estos caudales adicionales fueron recaudados valiéndose de la estructura ya establecida de gobierno en las jurisdicciones de Nueva España, por lo que no ocasionaron gastos adicionales a la Real Hacienda.

Por otro lado, el proceso de recaudación de donativos que se describió en esta investigación demuestra el peso político de las autoridades locales. Estas organizaban las colectas siguiendo preceptos generales, enviados desde la corte en México, pero tenían facultades para resolver las especificidades que se presentaran. Asimismo, queda patente la diversidad de tareas y funciones que desempeñaban en cada recolección. Como recolectores de datos que permitían tener un estimado de la riqueza en cada región, como recaudadores fiscales que recibían dinero y formaban relaciones esenciales para el control de las cajas reales y como agentes judiciales que aplicaban sanciones a quienes no acataran las órdenes. Sobre este último punto, hay que resaltar que las cantidades eran fijas, pero se halló al menos un caso en el que un propietario no donó la cantidad solicitada. Por otro lado, los alcaldes mayores fueron advertidos de recibir multas en caso de no cumplir con su comisión. Ambas penas fueron instrucciones del virrey, no una orden de la corona, lo que nuevamente demuestra el papel clave que cumplieron estos intermediarios entre el rey y sus súbditos. Como puede verse, valdría la pena estudiar más a fondo las recolecciones de donativos de las primeras décadas del xviII. Los estudios de solicitudes particulares y, más aún, los comparativos, nos permiten diversas aproximaciones a interacciones económicas y políticas de la fiscalidad hispánica.

Anexos

CUADRO 1. DONATIVOS DE LAS HACIENDAS DE NUEVA ESPAÑA POR
JURISDICGIÓN, 1710-1716 (EN PESOS)

\begin{tabular}{|c|c|}
\hline Jurisdicción & Donativo \\
\hline Celaya y Salvatierra & 11550 \\
\hline Atlixco & 7200 \\
\hline
\end{tabular}


Cholula

5325

Metepec e Yxtlahuaca

5250

Puebla

4942

Tlaxcala

4600

Sombrerete

3105

Maravatío

3100

Tacuba

3000

Pátzcuaro

2945

Toluca

2900

San Luis Potosí

2768

Marquesado del Valle

2449

San Miguel el Grande

2353

Tabasco

2250

Tehuacán

2150

Tochimilco

2131

Huichapa

2104

Oaxaca

2000

Cuautitlán

2000

Tulancingo

1975

Colima

1972

Querétaro

1756

Durango

1750

Malinalco

1734

Yzúcar

1650

Tula

1535

Pánuco y Tampico

1473

San Juan de los Llanos

1400

Guaxuapa

1386

Chicontepec

1356

Villa de Coyoacán

1300

Acatlán

1254

Minuatlán

1227

San Luis de la Paz

1200

Cuautla Amilpas

1192

Autla

1176

Villa del Nombre de Dios

1102

Jacona

1100

Villa de Córdova

1100

Guanajuato

1080

Zacualpa e Ycatecpan

1050

Teposcolula y Yanquitlán

1000

Coatepec

1000

Teposcolula

1000

Temascaltepec y Sultepec

950 
$\begin{array}{ll}\text { Tlazazalca } & 914\end{array}$

$\begin{array}{ll}\text { Orizaba } & 900\end{array}$

Chichicapa y Zimatlán $\quad 870$

Chilapa 850

San Juan Teotihuacan $\quad 822$

Tlalpujahua $\quad 800$

Tanzintaro y Pentzandaro $\quad 775$

$\begin{array}{ll}\text { Sayula } & 767\end{array}$

Zempoala $\quad 749$

Coatzacoalcos $\quad 687$

Nuevo Reino de León $\quad 670$

Zacatecas $\quad 650$

Ochipa $\quad 620$

Otumba 600

Teutitlán y Atempa $\quad 600$

Atitalaquia $\quad 562$

Mestitlán 471

San Cristóbal Ecatepec $\quad 450$

Yahualica 443

Xochimilco 400

Huauchinango 400

Apa 400

Tetela Minas $\quad 375$

Chietla $\quad 360$

Xiquilpa $\quad 350$

Mitla y Tlacolula $\quad 350$

Papantla 350

Zinagua y Laguacara $\quad 350$

Taxco $\quad 345$

Guadalcázar 313

Iguala $\quad 300$

Zacatlán 300

Zumpango de la Laguna $\quad 300$

Tepeapulco 300

Otupa 250

Ixmiquilpan $\quad 210$

Villa de León $\quad 200$

Huaxolotitlan 190

Zacatula 150

Lerma 150

Partido de Jaso y Tremendo $\quad 115$

$\begin{array}{ll}\text { Huejutla } & 101\end{array}$

Teotlalco 100

$\begin{array}{ll}\text { Niahuatlán } & 100\end{array}$ 
Villa alt

Huamelula

Ytiatlán

Peñoles

Teopontlán

Nochistlán

Xicayán

50

Mexicaltzingo

50

Ygualapa

Total

129383

Fuente: AGI, Contaduría, 748B fs.327-336; 820, fs.210-218.

\section{CUADRO 2. DONATIVOS DE HACENDADOS PARTICULARES DE NUEVA ESPAÑA, 1710-1714 (PESOS)}

\begin{tabular}{|c|c|c|}
\hline Nombre & Donativo & Propiedad \\
\hline Conde de Santiago & 350 & $\begin{array}{l}\text { Dueño de haciendas en distintas } \\
\text { jurisdicciones }\end{array}$ \\
\hline Monterde, Luis & 300 & $\begin{array}{l}\text { Dueño de haciendas en distintas } \\
\text { jurisdicciones }\end{array}$ \\
\hline Roldán, Bernabé Antonio & 200 & Dueño de dos haciendas en Apa \\
\hline Gómez Jaso, Juan & 150 & Dueño de hacienda en Tula \\
\hline Conde de Miravalle & 150 & Dueño de haciendas en Querétaro \\
\hline Cervantes, Juan Leonel de & 150 & $\begin{array}{l}\text { Apoderado de Francisco y Blas } \\
\text { de la Garza, dueños de hacienda y } \\
\text { rancho en el Nuevo Reino de León }\end{array}$ \\
\hline Fernández del Rivero, Antonio & 100 & Dueño de hacienda en San Luis Potosí \\
\hline Castañeda, Tomás & 100 & Dueño de hacienda en Huichapa \\
\hline Altamirano, Juan & 100 & $\begin{array}{l}\text { Dueño de hacienda en Atitalaquia } \\
\text { Dueño de hacienda de ovejas en }\end{array}$ \\
\hline Luyando y Bermero, Luis & 100 & Tlasasalca \\
\hline González del Pinal, Miguel & 100 & $\begin{array}{l}\text { Dueño de hacienda en San Miguel } \\
\text { el Grande }\end{array}$ \\
\hline Luna y Gorráez, Pedro & 100 & $\begin{array}{l}\text { Por su hacienda de ganado mayor } \\
\text { en Xicayán }\end{array}$ \\
\hline Alcorta, Pedro & 100 & Dueño de hacienda en Tepeaca \\
\hline Roca, Silvestre & 50 & Vecino de Tajimarca \\
\hline Ramón, Miguel & 50 & Dueño de rancho en Teopantlán \\
\hline Gorraez Beamont y Navarra, Francisco & 32 & \\
\hline Total: & 2132 & \\
\hline
\end{tabular}

Fuente: AGI, Contaduría, 748B fs.327-336. 


\section{LISTA DE REFERENCIAS}

Alcedo, A. de. (1789). Diccionario geográfico-histórico de las Indias Occidentales o América. Madrid: Imprenta de Manuel González.

Bautista y Lugo, G. (2020). Recaudar la lealtad al rey y proteger el dinero del reino. La ciudad de México entre servicios, arbitrios y crédito, 1623-1629. En G. del Valle (ed.), Negociación, lágrimas y maldiciones. La fiscalidad extraordinaria en la monarquía hispánica, 1620-1814b. México: Instituto Mora.

Borah, W. W. (2002). El gobierno provincial en la Nueva España, 1570-1787. México: Universidad Nacional Autónoma de México.

Domínguez Ortíz, Antonio (1960). Política y hacienda de Felipe IV. Madrid: Editorial de Derecho financiero.

Escamilla, I. (2003). La nueva alianza: El Consulado de México y la monarquía borbónica durante la guerra de Sucesión. En G. del Valle (ed.), Mercaderes, comercio y consulados de Nueva España en el siglo хиIII (pp. 41-63). México: Instituto Mora.

Escamilla, I. (2011). Los intereses malentendidos: El Consulado de Comerciantes de México y la monarquía española, 1700-1739. México: Universidad Nacional Autónoma de México.

Garavaglia, J. C. y Grosso, J. C. (1994). Puebla desde una perspectiva microhistórica: La villa de Tepeaca y su entorno agrario: población, producción e intercambio, 1740-1870. México: Claves Latinoamericanas.

Garritz, A. (1993). Guía del Archivo Moctezuma-Miravalle. México: Universidad Nacional Autónoma de México.

Gelabert, J. E. (1997). La bolsa del rey: Rey, reino y fisco en Castilla (1598-1648). Barcelona: Crítica.

Gerhard, P. (1986). Geografía histórica de la Nueva España, 1519-1821. México: Universidad Nacional Autónoma de México.

Gil, F. (2015). De la negociación a la coerción: La recaudación del donativo de 1635. Studia Historica: Historia Moderna, 37(0), 211-234. DoI: 10.14201/shhmo201537211234

Goyas, R. (2015). Las composiciones de tierras de 1643 en Nueva España. Revista de Historia Iberoamericana, 8(2), 54-75.

Lanza, R. (2010). El donativo de 1629 en la Andalucía bética. Studia Historica: Historia Moderna, $32,179-277$.

Marichal, C. (1999). La bancarrota del virreinato, Nueva España y las finanzas del imperio español, 1780-1810. México: El Colegio de México/Fondo de Cultura Económica.

Mörner, M. (1975). La hacienda hispanoamericana: Examen de las investigaciones y debates recientes. En E. Florescano (ed.), Haciendas, latifundios y plantaciones en América Latina (pp. 1546). México: Siglo XXI.

Nardi, L. de (2018a). El carácter voluntario de los donativos indianos, entre la praxis institucional y la construcción del consenso (siglos XVI-XVII). Historia Mexicana, 46(4), 1535-1596. DoI: $10.24201 / \mathrm{hm} . v 67 \mathrm{i} 4.3564$

Nardi, L. de (2018b). Los donativos voluntarios: Un aspecto poco estudiado de la política americana de los Habsburgo de España (siglos XVI-XvII). América Latina en la Historia Económica, 25(1), 7-35. Dor: 10.18232/alhe.857

Nieves, E. (2018). Recursos extraordinarios para la defensa de la monarquí: La respuesta de los vecinos de la ciudad de México al donativo universal de 1798 (Tesis inédita de licenciatura). Universidad Nacional Autónoma de México, México. 
Nieves, E. (2020a). El donativo universal de 1798 en Nueva España: Medidas y estrategias para su recolección. En G. del Valle (ed.), Negociación, lágrimas y maldiciones. La fiscalidad extraordinaria en la Monarquía Hispánica, 1620-1814b. México: Instituto Mora.

Nieves, E. (2020b). Servicios correspondientes "a lo que piden las urgencias": Los donativos solicitados en Nueva España y Filipinas durante la guerra de Sucesión (1701-1714) (Tesis inédita de maestría). Instituto Mora, México.

Pérez-Mallaína, P. E. (1982). Política naval española en el Atlántico, 1700-1715. Sevilla: Escuela de Estudios Hispano-Americanos.

Torales, M. C. (2005). Tierras de indios, tierras de españoles: Confirmación y composición de tierras y aguas en la jurisdicción de Cholula (siglos XVI-XVIII). México: Universidad Iberoamericana.

Torres, R. (2013). El precio de la guerra: El estado fiscal-militar de Carlos III (1779-1783). Madrid: Marcial Pons.

Truchuelo, S. (2008). Privilegios y libertades fiscales: Los donativos al monarca en los territorios vascos y Cataluña en el periodo altomoderno. Prebaldes: Revista d'Història Moderna, 28, 283300.

Valle, G. del (1997). El Consulado de comerciantes de la ciudad de México y las finanzas novohispanas, 1592-1827 (Tesis inédita de doctorado). El Colegio de México, México.

Valle, G. del (1998). El apoyo financiero del consulado de comerciantes a las guerras españolas del siglo XviII. En P. Martínez y G. del Valle (eds.), El crédito en Nueva España (pp. 131-150). México: Instituto Mora.

Valle, G. del (2009). Servicios fiscales y financieros del consulado de comerciantes de la ciudad de México en los siglos XviI y xviII. En G. Garza y J. Sobrino (eds.), Evolución del sector servicios en ciudades y regiones de México (pp. 95-117). México: Colegio de México.

Valle, G. del (2016a). Donativos, préstamos y privilegios: Los mercaderes y mineros de la ciudad de México durante la guerra angloespañola de 1779-1783. México: Instituto Mora.

Valle, G. del (2016b). Servicios financieros del Consulado de México para la guerra de Sucesión dinástica. En A. Dubet y S. Solbes (eds.), La construcción de la Hacienda hispánica en el largo siglo XVIII (pp. 77-88). Madrid: Casa de Velázquez.

Valle, G. del (2020). Lágrimas y maldiciones: La intermediación financiera del consulado de México al servicio de la monarquía hispánica, 1680-1708. En G. del Valle (ed.), Negociación, lágrimas y maldiciones. La fiscalidad extraordinaria en la monarquía hispánica, 1620-1814b. México: Instituto Mora.

Wobeser, G. V. (1989). La formación de la hacienda en la época colonial: El uso de la tierra y el agua. México: Universidad Nacional Autónoma de México.

Yuste, C. (2002). Las autoridades locales como agentes del fisco en Nueva España. En W. W. Borah (ed.), El gobierno provincial en Nueva España, 1570-1787 (pp. 117-134). México: Universidad Nacional Autónoma de México.

\section{OTRAS FUENTES}

\section{Bibliografía}

Ciaramitaro, F., y Nardi, L. de (2019). El régimen fiscal de los donativos en las Indias como alternativa a las asambleas estamentarias europeas: Una reinterpretación del imperio (siglos XVI y XVII). Mexican Studies/Estudios Mexicanos, 35(3), 300-326. DoI: 10.1525/msem.2019.35.3.300 


\section{Archivos}

AGI Archivo General de Indias, Sevilla, España.

AGN Archivo General de la Nación, Ciudad de México, México. 